\title{
BMJ Open Chinese herbal medicine for resistant hypertension: a systematic review
}

\author{
Xingjiang Xiong, ${ }^{1}$ Xiaoke $\mathrm{Li}^{2}{ }^{2}$ Yuqing Zhang, ${ }^{3}$ Jie Wang ${ }^{1}$
}

To cite: Xiong $X$, Li X, Zhang $Y$, et al. Chinese herbal medicine for resistant hypertension: a systematic review. BMJ Open 2015;5: e005355. doi:10.1136/ bmjopen-2014-005355

- Prepublication history for this paper is available online. To view these files please visit the journal online (http://dx.doi.org/10.1136/ bmjopen-2014-005355).

Received 9 April 2014 Revised 29 September 2014 Accepted 3 October 2014

CrossMark

For numbered affiliations see end of article.

\section{Correspondence to} Dr Xingjiang Xiong; xiongxingjiangtcm@163.com, 5administration@163.com

\section{ABSTRACT}

Objectives: This study aimed to summarise the current evidence from randomised control trials (RCTs) concerning treatment of patients with resistant hypertension with Chinese herbal medicine (CHM). Design: Seven databases, including the Cochrane Library, PubMed, EMBASE, CNKI, VIP, CBM and Wanfang, were systematically searched from their inception to March 2014 for RCTs investigating treatment of resistant hypertension in which CHM was used either as a monotherapy or in combination with conventional medicine versus placebo, no intervention or conventional medicine.

Results: Five trials containing 446 hypertensive patients were identified. The methodological quality of most trials was evaluated as generally low. All included trials compared CHM plus antihypertensive drugs with antihypertensive drugs alone for resistant hypertension. Formulations of CHM included tablet, decoction and injection. It was found that, compared with antihypertensive drugs alone, CHM (tablet) plus antihypertensive drugs resulted in clinically, but not statistically, significant reductions in systolic blood pressure (SBP; weighted mean difference $(\mathrm{WMD})=$ $-10.32 \mathrm{~mm} \mathrm{Hg} ; 95 \% \mathrm{Cl}-21.10$ to $0.46 ; p=0.06)$ and diastolic blood pressure (DBP; WMD $=-3.30 \mathrm{~mm} \mathrm{Hg}$; $95 \% \mathrm{Cl}-7.66$ to $1.06 ; \mathrm{p}=0.14)$. CHM (decoction) plus antihypertensive drugs also produced a clinically meaningful, but not statistically significant, reduction in $\mathrm{SBP}$ (WMD $=-12.56 \mathrm{~mm} \mathrm{Hg} ; 95 \% \mathrm{Cl}-26.83$ to 1.71 ; $\mathrm{p}=0.08$ ), and did significantly decrease DBP (WMD= $-7.89 \mathrm{~mm} \mathrm{Hg} ; 95 \% \mathrm{Cl}-11.74$ to $-4.04 ; \mathrm{p}<0.0001)$. There were no significant differences in SBP (WMD= $-3.50 \mathrm{~mm} \mathrm{Hg} ; 95 \% \mathrm{Cl}-8.95$ to $1.95 ; \mathrm{p}=0.21$ ) and DBP (WMD $=1.00 \mathrm{~mm} \mathrm{Hg} ; 95 \% \mathrm{Cl}-1.39$ to 3.39 ; $\mathrm{p}=0.41$ ) between $\mathrm{CHM}$ (injection) plus the antihypertensive drugs group and antihypertensive drugs alone. The safety of CHM remained uncertain. Conclusions: No definite conclusions about the effectiveness and safety of $\mathrm{CHM}$ for resistant hypertension could be drawn. More rigorously designed trials are warranted.

\section{INTRODUCTION}

Effective control of blood pressure (BP) in patients with hypertension decreases the incidence of all-cause and cardiovascular mortality, sudden death, stroke, coronary heart disease, heart failure, atrial fibrillation, peripheral

\section{Strengths and limitations of this study}

The strength of this systematic review is its comprehensive, unbiased search of various databases, including the four main Chinese databases, without language and publication restrictions.

- The included trials were small with significant heterogeneity.

- This systematic review reached no definite conclusions about the effectiveness and safety of CHM for resistant hypertension.

artery disease and renal insufficiency. ${ }^{1}{ }^{2}$ However, many hypertensive patients are unresponsive to standard antihypertensive care. ${ }^{3} 4$ Since the publication of a scientific statement from the American Heart Association (AHA) on the evaluation and treatment of resistant hypertension in 2008, there has been growing clinical and research interest in the epidemiology, pathophysiology and management of resistant hypertension. ${ }^{5}$ Resistant hypertension is defined as a failure to achieve a BP goal of $<140 / 90 \mathrm{~mm} \mathrm{Hg}$, despite treatment with a diuretic and $\geq$ three different antihypertensive medication classes at maximally tolerated dosages. ${ }^{6}$ Resistant hypertension is currently a devastating medical, social and economic problem. Despite knowledge about the management of resistant hypertension and the availability of numerous effective antihypertensive drugs and combinations of drugs, it remains a concern for both primary care clinicians and specialists. ${ }^{78}$ Therefore, some patients choose non-conventional therapy to prevent and manage resistant hypertension. ${ }^{9}$ There is robust evidence of the BP-lowering effects of complementary therapies, including aerobic exercise ${ }^{10}$ tai chi, ${ }^{11}$ qigong, ${ }^{12}$ yoga ${ }^{13}$ acupuncture, ${ }^{14}$ moxibustion, ${ }^{15}$ cupping, ${ }^{16}$ massage ${ }^{17}$ dietary Fments ${ }^{18}$ and herbal medicine. ${ }^{19} 20$

Chinese herbal medicine (CHM), one of the most important components of traditional Chinese medicine (TCM), is widely used in East Asia. ${ }^{21} \mathrm{CHM}$ has been used for more than 3000 years and has unique concepts concerning aetiologies and systems of diagnosis and 
treatment. ${ }^{22}$ There has been continuing interest in the role of CHM in managing resistant hypertension. ${ }^{23-25} \mathrm{CHM}$ has the potential to complement conventional Western medical treatment by improving efficacy with few adverse events (AEs). CHM, either alone or as an adjunct to antihypertensive drugs, is widely used by TCM practitioners in China. Many clinical studies ranging from case series to clinical trials have reported that CHM improves signs and symptoms, decreases BP and modifies cardiovascular risk factors in patients with resistant hypertension. ${ }^{26-28}$ However, there are still uncertainties concerning the efficacy of CHM because of the lack of high-quality, largesample randomised controlled trials (RCTs). To the best of our knowledge, there is no critically appraised evidence, such as a systematic review or meta-analysis, of the benefits and safety of CHM for resistant hypertension. Therefore, we aimed to systematically review published and unpublished RCTs to ascertain the role of CHM in treatment of resistant hypertension.

\section{METHODS}

\section{Search strategies}

The following electronic databases were searched from their inception until 17 March 2014: the Cochrane Library (March 2014), PubMed (1959-2014), EMBASE (19802014), Chinese National Knowledge Infrastructure (CNKI, 1980-2014), VIP information database (1989-2014), Chinese Biomedical Literature Database (CBM, 19782014) and Wanfang Data Information Site (1998-2014). Since CHM is widely used in China, published reports listed in the four main Chinese electronic databases were retrieved to identify the maximum possible number of trials. Ongoing clinical trials registered on the website of the Chinese Clinical Trial Register (available at: http:// www.chictr.org/) and the international clinical trial registry of the US. National Institutes of Health (available at: http://clinicaltrials.gov/) were also searched.

Keywords for database searching were ("resistant hypertension" OR "hypertension" OR "high blood pressure" OR "blood pressure") AND ("traditional Chinese medicine" OR "Chinese herbal medicine" OR "Chinese herb" OR "herbal medicine" OR "herb therapy") AND ("clinical trial" OR "randomized controlled trial"). Additionally, conference proceedings relevant to this topic, references from relevant clinical trials and review articles were manually searched in an attempt to retrieve all potentially relevant published and unpublished articles.

\section{Participants}

Patients enrolled in the studies were required to meet at least one of the current or past guidelines for or definitions of resistant hypertension. ${ }^{5}{ }^{6}$ No restrictions were imposed on age, sex or ethnicity.

\section{Interventions}

CHM was defined as a decoction, tablet, pill, powder, granule, capsule, oral liquid or injection that originated from botanical herbal products according to the Pharmacopoeia of the People's Republic of China (2010 edition). All prospective RCTs comparing CHM used alone or in combination with conventional medicine versus placebo, no intervention or conventional medicine for resistant hypertension were included in this review, regardless of blinding, publication status or language. Trials investigating the effect of any type of CHM, with or without conventional medicine, in patients with resistant hypertension were included. Trials using CHM concomitantly with other types of complementary therapies such as tai chi, qigong, acupuncture, moxibustion, cupping and massage were excluded.

Interventions in the control group included conventional Western medicine, placebo or no intervention without restriction on dosage, formulations or frequency. Trials comparing CHM with other complementary therapies were excluded, as were case reports, case series, quasi-randomised trials, animal experiments and duplicated publications. It was required that patients in the treatment group had been treated with the same type and dosage of conventional therapy according to the same standards as that used in the control group. The duration of treatment was required to be more than 2 weeks.

\section{Outcome measures}

$\mathrm{BP}$ and $\mathrm{AEs}$ were required to be reported as the main outcome measures at the end of the treatment.

\section{Data extraction}

Two independent reviewers read the titles and abstracts of references that appeared promising based on predefined selection criteria. Full articles were retrieved for further assessment. Reasons for exclusion of studies were recorded. After the final selections had been made, two reviewers independently extracted the data from the eligible studies. The data extraction form comprised the following items: (1) general information about the article, including authors, title, year of publication and source; (2) patient characteristics, including sample size, age and sex of the participants and diagnosis standard; (3) characteristics of the included trials, including random sequence generation, allocation concealment, blinding, intention-to-treat analysis, reporting of dropouts or withdrawals, interventions in the treatment and control groups and duration of treatment; (4) outcomes, including BP data at baseline and after treatment; (5) length and frequency of follow-up; and (6) AEs. The authors were contacted by email, fax or telephone concerning any missing or confusing information about the trials. Disagreements were resolved by discussion and consensus was reached with a third party.

\section{Quality assessment}

The 'risk of bias' criteria according to the guidelines of the Cochrane Handbook for Systematic Review of Interventions were assessed to evaluate the methodological quality of 
the included studies. ${ }^{29}$ The following domains were evaluated: random sequence generation (selection bias), allocation concealment (selection bias), blinding of participants and personnel (performance bias), blinding of outcome assessment (detection bias), incomplete outcome data (attrition bias), selective reporting (reporting bias) and other bias. The evaluated domains were judged as 'low', 'unclear' or 'high' risk of bias according to the criteria of the Cochrane guidelines. The trials were then categorised into three levels: low risk of bias (all items at low risk of bias), high risk of bias (at least one item at high risk of bias) or unclear risk of bias (at least one item unclear). Discrepancies were resolved by discussion between the four reviewers.

\section{Statistical analysis}

Mean changes in BP data between baseline and after intervention were used to assess differences between the treatment and control groups. Since all outcomes were continuous data, they were presented as weighted mean difference (WMD) and its 95\% CI. WMD and 95\% CI were calculated using Revman V.5.1 software provided by the Cochrane Collaboration (Copenhagen: The Nordic Cochrane Centre, Cochrane Collaboration, 2011). Heterogeneity was assessed by the $\mathrm{I}^{2}$ statistic and was considered to be significant when $\mathrm{I}^{2}$ was $>50 \%$. The fixed effects model was used to analyse data that were not significantly heterogeneous, whereas the random effects model was used where there was significant heterogeneity $\left(\mathrm{I}^{2}>50 \%\right)$. $\mathrm{p}<0.05$ was considered statistically significant. If a sufficient number of studies (at least 10) were available, an attempt was made to assess publication bias by using funnel plots.

\section{RESULTS}

\section{Descriptions of trials}

The flow chart in figure 1 depicted the search process and study selection. Primary searches of the seven electronic databases yielded 1826 potentially relevant articles. After removal of 1093 duplicates, 733 articles remained. After reading the subjects and abstracts of these 733 articles, 695 were excluded for at least one of the following reasons: (1) not a clinical trial; (2) case report; (3) lack of control group; and (4) efficacy of CHM not being the objective of the study. The full texts of the remaining 38 articles were retrieved and another 33 excluded for the following reasons: participants did not meet the inclusion criteria $(n=27)$, no control group $(n=3)$, duplication $(n=2)$ and no data for extraction $(n=1)$. Thus, five eligible studies were ultimately included. ${ }^{30-34}$ All five trials had been performed in China and their findings published in Chinese.

The basic characteristics of these studies were summarised in table 1 . They included 446 patients in all. All trials used CHM as adjunctive therapy for resistant hypertension. Interventions included CHM combined with antihypertensive drugs, whereas controls included
PRISMA 2009 Flow Diagram

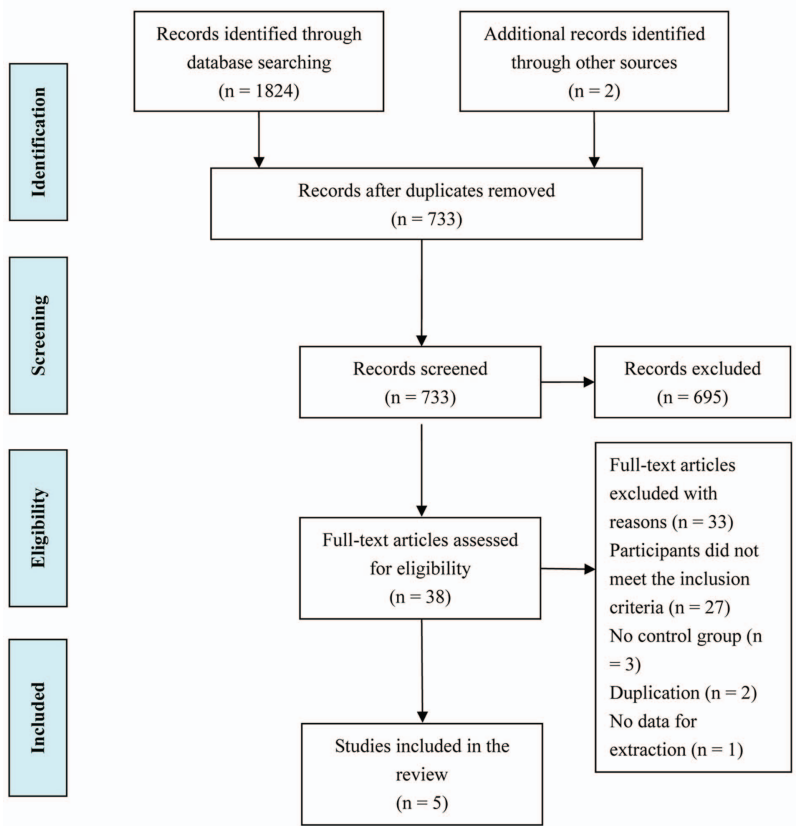

Figure 1 PRISMA 2009 flow diagram.

antihypertensive drug therapy alone. Formulations of CHM included tablet, ${ }^{30}{ }^{32}$ decoction $^{31}{ }^{34}$ and injection. ${ }^{33}$ The duration of treatment ranged from 4 to 24 weeks. The compositions of the CHM used in each study are presented in table 2. The effects on BP were reported by all five studies; however, AEs were only reported in one of them. ${ }^{30}$

\section{Quality of the included studies}

The criteria recommended by the Cochrane Handbook for Systematic Reviews were used to assess the risk of bias of the five trials. The majority of studies were assessed to be of generally poor methodological quality (figure 2). All trials declared randomisation; however, none reported the methods used to generate allocation sequences (such as random number tables). Allocation concealment was not reported by all included trials. One trial reported blinding of participants and personnel. ${ }^{32}$ However, no trial described blinding of the outcome assessment. One trial used a placebo control. $^{32}$ No trial reported intention-to-treat analyses, dropouts or pretrial estimations of sample size.

\section{Estimates of effects on outcomes in terms of BP}

All studies focused on the effects of CHM on resistant hypertension. Subgroup analysis was performed according to the different forms of CHM, namely tablet, ${ }^{30} 32$ decoction $^{31}{ }^{34}$ and injection. ${ }^{33}$

\section{Tablet}

Two RCTs compared CHM (tablet) plus antihypertensive drugs with antihypertensive drugs alone. ${ }^{30}{ }^{32}$ One trial conducted by Huang et $a l^{80}$ assessed the effectiveness of 


\begin{tabular}{|c|c|c|c|c|c|c|c|c|c|}
\hline Study ID & $\begin{array}{l}\text { Sample size } \\
\text { (randomised/ } \\
\text { analysed) } \\
\text { M/F }\end{array}$ & $\begin{array}{l}\text { Age } \\
\text { (years) }\end{array}$ & $\begin{array}{l}\text { Diagnosis } \\
\text { standard }\end{array}$ & Intervention & Control & $\begin{array}{l}\text { During of } \\
\text { treatment }\end{array}$ & $\begin{array}{l}\text { Main } \\
\text { outcomes } \\
\text { (intergroup } \\
\text { differences) }\end{array}$ & $\begin{array}{l}\text { Adverse } \\
\text { effects report }\end{array}$ & $\begin{array}{l}\text { Main findings from } \\
\text { original study }\end{array}$ \\
\hline Huang et $a l^{30}$ & $\begin{array}{l}185 / 185 \\
T: 52 / 40 \\
C: 51 / 42\end{array}$ & $\begin{array}{l}\text { T: } 52.9 \\
\pm 7.0 \\
\text { C: } 54.3 \\
\pm 6.4\end{array}$ & CGMH-2004 & $\begin{array}{l}\text { Radix Salviae } \\
\text { Miltiorrhizae } \\
\text { tablet (4 tablets, } \\
3 \text { times/day) } \\
\text { +control }\end{array}$ & $\begin{array}{l}\text { Hydrochlorothiazide ( } 10 \mathrm{mg} \\
\text { four time a day)+candesartan } \\
\text { cilexetil capsules ( } 8 \mathrm{mg} \text { four } \\
\text { times a day)+nifedipine } \\
(10 \mathrm{mg} \text { twice daily) } \\
\text { +atorvastatin tablet ( } 10 \mathrm{mg} \\
\text { four times a day)* }\end{array}$ & 24 weeks & $\begin{array}{l}\text { SBP and } \\
\text { DBP: } p<0.05\end{array}$ & $\begin{array}{l}\text { Y } \\
\text { T: distending } \\
\text { feeling in head (2 } \\
\text { cases) } \\
\text { C: nausea, } \\
\text { vomiting and other } \\
\text { gastrointestinal } \\
\text { reactions (2 } \\
\text { cases) }\end{array}$ & $\begin{array}{l}\text { Long-term use of Radix } \\
\text { Salviae Miltiorrhizae tablet } \\
\text { can improve BP and blood } \\
\text { lipids for resistant } \\
\text { hypertension; however, as } \\
\text { complementary therapies, } \\
\text { it could enhance the } \\
\text { antihypertensive effect } \\
\text { more significantly. }\end{array}$ \\
\hline Wang and Zheng ${ }^{31}$ & $\begin{array}{l}98 / 98 \\
\text { T: } 38 / 24 \\
\text { C: } 19 / 17\end{array}$ & $\begin{array}{l}\mathrm{T}: 41.5 \\
\pm 11.2 \\
\mathrm{C}: 42.5 \\
\pm 13.4\end{array}$ & CGMH-2004 & $\begin{array}{l}\text { Decoction of } \\
\text { Radix Angelicae } \\
\text { Sinensis and } \\
\text { Radix Astragali } \\
(300 \mathrm{~mL} / \mathrm{d}) \\
\text { +control }\end{array}$ & $\begin{array}{l}\text { Hydrochlorothiazide ( } 25- \\
50 \text { mg four times a day) } \\
\text { + metoprolol tartrate ( } 50 \mathrm{mg} \\
\text { twice daily)+nifedipine } \\
\text { controlled release tablet ( } 30- \\
60 \text { mg four times a day) } \\
\text { +benazepril hydrochloride } \\
\text { tablet ( } 10 \mathrm{mg} \text { four times a } \\
\text { day) } \dagger\end{array}$ & 4 weeks & $\begin{array}{l}\text { SBP and } \\
\text { DBP: } p<0.05\end{array}$ & $\mathrm{~N}$ & $\begin{array}{l}\text { Decoction of Radix } \\
\text { Angelicae Sinensis and } \\
\text { Radix Astragali combined } \\
\text { with antihypertensive } \\
\text { drugs may reduce BP, } \\
\text { improve cardiac function, } \\
\text { modulate blood lipids } \\
\text { metabolism and regulate } \\
\text { blood viscosity. }\end{array}$ \\
\hline Zhang et $a{ }^{32}$ & $\begin{array}{l}40 / 40 \\
\mathrm{~T}: 27 \\
\mathrm{C}: 13\end{array}$ & $\begin{array}{l}57.8 \\
\pm 9.60 \\
(T / C: \\
\text { NR) }\end{array}$ & $\begin{array}{l}1978 \\
\text { WHO-ISH } \\
\text { GMH }\end{array}$ & $\begin{array}{l}\text { Ganoderma } \\
\text { Lucidumseu } \\
\text { Sinensis tablet } \\
\text { (110 mg, } 3 \\
\text { times/day) } \\
\text { +control }\end{array}$ & $\begin{array}{l}\text { Antihypertensive drugs (no } \\
\text { detailed information about } \\
\text { dosage) }\end{array}$ & 3 months & $\begin{array}{l}\text { SBP and } \\
\text { DBP: } p<0.01\end{array}$ & $\mathrm{~N}$ & $\begin{array}{l}\text { Ganoderma Lucidumseu } \\
\text { Sinensis tablet was } \\
\text { particularly beneficial for } \\
\text { the treatment of resistant } \\
\text { hypertension with } \\
\text { hyperviscosity and } \\
\text { hyperglycaemia. It is also } \\
\text { helpful to prevent and } \\
\text { relieve complications in } \\
\text { hypertension. }\end{array}$ \\
\hline Zhang et $a{ }^{\beta 3}$ & $\begin{array}{l}63 / 63 \\
T: 30 / 3 \\
C: 27 / 3\end{array}$ & $\begin{array}{l}\text { T: } 80.9 \\
\pm 3.7 \\
\text { C: } 79.0 \\
\pm 4.7\end{array}$ & $\begin{array}{l}1999 \\
\text { WHO-ISH } \\
\text { GMH }\end{array}$ & $\begin{array}{l}\text { NS } 250 \mathrm{~mL} \\
\text { +gastrodin } \\
\text { injection }(20 \mathrm{~mL} / \\
\text { day)+control }\end{array}$ & $\begin{array}{l}\text { Amlodipine, irbesartan and } \\
\text { hydrochlorothiazide (no } \\
\text { detailed information about } \\
\text { dosage) }\end{array}$ & 4 weeks & $\begin{array}{l}\text { SBP and } \\
\text { DBP: } p>0.05\end{array}$ & $\mathrm{~N}$ & $\begin{array}{l}\text { Gastrodin injection was } \\
\text { beneficial to old patients } \\
\text { with refractory } \\
\text { hypertension, and can } \\
\text { improve the balance of ET } \\
\text { and NO levels in plasma. }\end{array}$ \\
\hline $\mathrm{Yan}^{34}$ & $\begin{array}{l}60 / 60 \\
T: 17 / 13 \\
\text { C: } 16 / 14\end{array}$ & $\begin{array}{l}\mathrm{T}: \\
56.43 \\
\pm 8.21 \\
\mathrm{C}: \\
57.52 \\
\pm 8.33\end{array}$ & CGMH-2004 & $\begin{array}{l}\text { Chinese herbal } \\
\text { medicine }(1 \\
\text { dose/day) } \\
+ \text { control }\end{array}$ & $\begin{array}{l}\text { Diuretics }+\mathrm{ACE}+\beta \text {-blockers, } \\
\text { and/or dihydropyridine } \\
\text { calcium antagonists }\end{array}$ & 1 month & $\begin{array}{l}\text { SBP and } \\
\text { DBP: } p<0.01\end{array}$ & $\mathrm{~N}$ & $\begin{array}{l}\text { Chinese herbal medicine } \\
\text { combined with } \\
\text { antihypertensive drugs } \\
\text { was effective in lowering } \\
\text { BP in patients with } \\
\text { resistant hypertension. }\end{array}$ \\
\hline
\end{tabular}

*Another class of antihypertensive drugs may be combined when blood pressure control is not satisfied.

†Taking at least two kinds of antihypertensive drugs.

C, control group; CGMH-2004, Chinese Guidelines for the Management of Hypertension-2004; N, no; NR, not reported; NS, normal saline; T, treatment group; WHO-ISH GMH, WHO-ISH guidelines for the management of hypertension; $\mathrm{Y}$, yes. 
Table 2 Composition of Chinese herbal medicine used in the studies

\begin{tabular}{|c|c|c|}
\hline Study ID & Chinese herbal medicine & Composition of Chinese herbal medicine \\
\hline Huang et $a l^{\beta 0}$ & Radix Salviae Miltiorrhizae tablet & Radix Salviae Miltiorrhizae (Danshen, Danshen Root) \\
\hline Wang and & Decoction of Radix Angelicae & Radix Angelicae Sinensis (Danggui, Chinese Angelica) $15 \mathrm{~g}$, Radix \\
\hline Zheng $^{31}$ & Sinensis and Radix Astragali & $\begin{array}{l}\text { Astragali (Huangqi, Root) } 15 \mathrm{~g}, \text { Rhizoma Gastrodiae (Tianma, Tall } \\
\text { Gastrodia Tuber) } 10 \mathrm{~g} \text { and Stigma Maydis (Yumixu, Corn Stigma) } 60 \mathrm{~g}\end{array}$ \\
\hline Zhang et $a \beta^{\beta 2}$ & $\begin{array}{l}\text { Ganoderma Lucidumseu Sinensis } \\
\text { tablet }\end{array}$ & Ganoderma lucidum polysaccharides \\
\hline Zhang et $a l^{\beta 3}$ & Gastrodin injection & Gastrodin/4-Hydroxybenzyl alcohol 4-O- $\beta$-D-glucoside \\
\hline $\operatorname{Yan}^{34}$ & Chinese herbal medicine & $\begin{array}{l}\text { Radix Astragali (Huangqi, Root) } 30 \mathrm{~g} \text {, Radix Angelicae Sinensis } \\
\text { (Danggui, Chinese Angelica) } 12 \mathrm{~g} \text {, Radix Paeoniae Rubra (Chishao, } \\
\text { Red Paeony Root) } 9 \mathrm{~g} \text {, Rhizoma Chuanxiong (Chuanxiong, Szechuan } \\
\text { Lovage Rhizome) } 9 \mathrm{~g} \text {, Semen Persicae (Taoren, Peach Seed) } 6 \mathrm{~g} \text {, Flos } \\
\text { Carthami (Honghua, Safflower) } 6 \mathrm{~g} \text {, Radix Platycodi (Jiegeng, } \\
\text { Platycodon Root) } 6 \mathrm{~g} \text { and Fructus Aurantii (Zhike, orange fruit) } 6 \mathrm{~g}\end{array}$ \\
\hline
\end{tabular}

the Radix Salviae Miltiorrhizae tablet on patients with resistant hypertension complicated with hyperlipidaemia. Another trial performed by Zhang $e t a l^{32}$ evaluated the therapeutic effects of the Ganoderma Lucidum Seu Sinensis tablet on resistant hypertension with hyperviscosity and hyperglycaemia. Meta-analysis of these two trials showed no difference between CHM (tablet) plus antihypertensive drugs and antihypertensive drugs alone in decreasing $\mathrm{SBP}(\mathrm{WMD}=-10.32 \mathrm{~mm} \mathrm{Hg} ; 95 \%$ CI -21.10 to $0.46 ; \mathrm{p}=0.06$ ) or $\mathrm{DBP}(\mathrm{WMD}=-3.30 \mathrm{~mm} \mathrm{Hg}$; $95 \% \mathrm{CI}-7.66$ to $1.06 ; \mathrm{p}=0.14)$, with $\mathrm{I}^{2}$ values ranging from 61 to $78 \%$ (figure $3 \mathrm{~A}$ ).

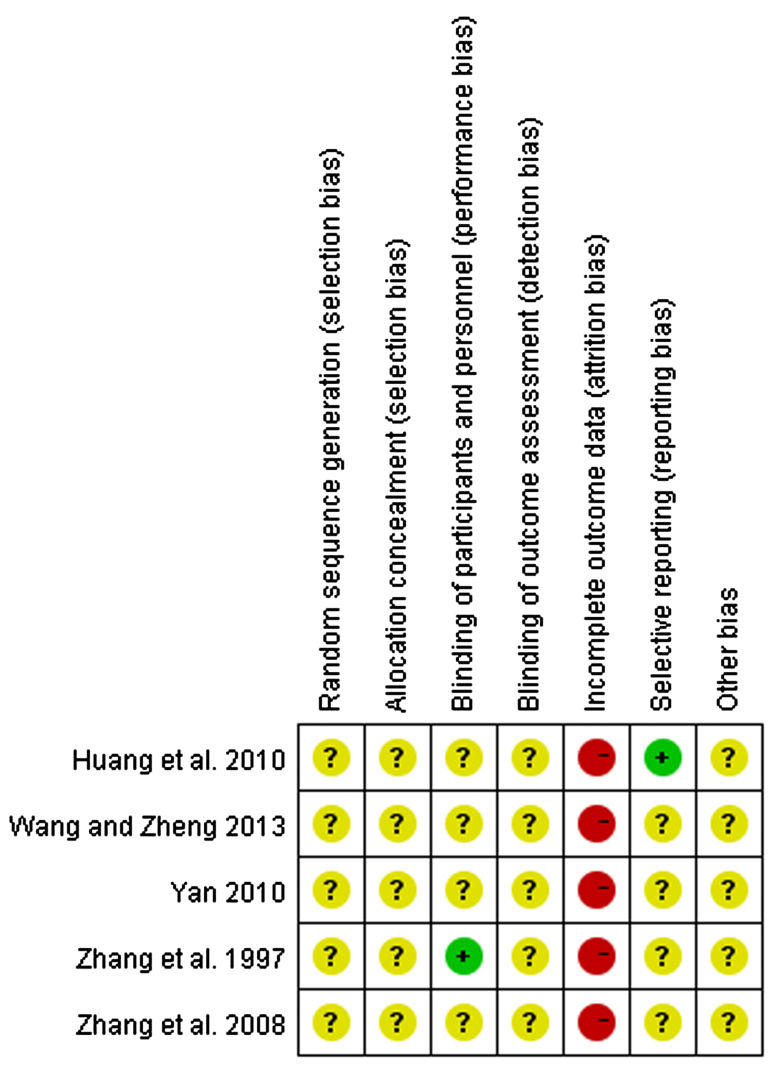

Figure 2 Risk of bias summary.

\section{Decoction}

Two trials compared CHM (decoction) plus antihypertensive drugs with antihypertensive drugs alone. ${ }^{31} 34$ One trial, performed by Wang and Zheng, ${ }^{31}$ evaluated the effects of a decoction of Radix Angelicae Sinensis and Radix Astragali plus antihypertensive drugs on resistant hypertension. The other trial, performed by Yan, ${ }^{34}$ reported the effect of CHM (decoction for supplementing qi and activating blood circulation) combined with antihypertensive drugs on BP compared with antihypertensive drugs alone. Meta-analysis of these two trials revealed no significant difference between the treatment and control groups on decreasing SBP (WMD=-12.56 $\mathrm{mm} \mathrm{Hg} ; 95 \%$ CI -26.83 to $1.71 ; \mathrm{p}=0.08)$ with high heterogeneity $\left(\chi^{2}=4.48\right.$, $\left.\mathrm{p}=0.03 ; \quad \mathrm{I}^{2}=78 \%\right)$; however, $\mathrm{DBP}$ was significantly reduced $(\mathrm{WMD}=-7.89 \mathrm{~mm} \mathrm{Hg} ; 95 \%$ CI -11.74 to $-4.04 ; \mathrm{p}<0.0001)$ with no heterogeneity $\left(\chi^{2}=1.12\right.$, $\left.\mathrm{p}=0.29 ; \mathrm{I}^{2}=11 \%\right)$, more so by the CHM (decoction) plus antihypertensive drugs than by the antihypertensive drugs alone (figure 3B).

\section{Injection}

One RCT performed by Zhang et $a l^{33}$ compared CHM (gastrodin injection) plus antihypertensive drugs with antihypertensive drugs alone. Meta-analysis showed no significant decrease in SBP (WMD=-3.50 $\mathrm{mm} \mathrm{Hg} ; 95 \%$ CI -8.95 to $1.95 ; \mathrm{p}=0.21)$ or $\mathrm{DBP}(\mathrm{WMD}=1.00 \mathrm{~mm} \mathrm{Hg}$; $95 \%$ CI -1.39 to $3.39 ; \mathrm{p}=0.41)$ in the study patients (figure 3C).

\section{Adverse events}

With increasing reports of liver and kidney toxicity caused by CHM, its safety is being scrutinised. ${ }^{35-37} \mathrm{AE}$ monitoring was reported in detail by only one of the trials $^{30}$ reviewed; the other four studies did not mention AEs. Huang et al reported that AEs occurred in two patients in the Radix Salviae Miltiorrhizae tablet group. Symptoms included a distending feeling in the head. There were also two patients with AEs in the control 
A Tablet

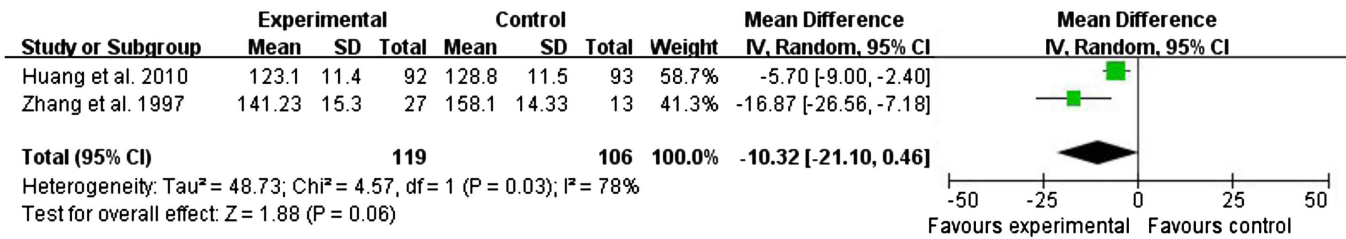

(a) SBP

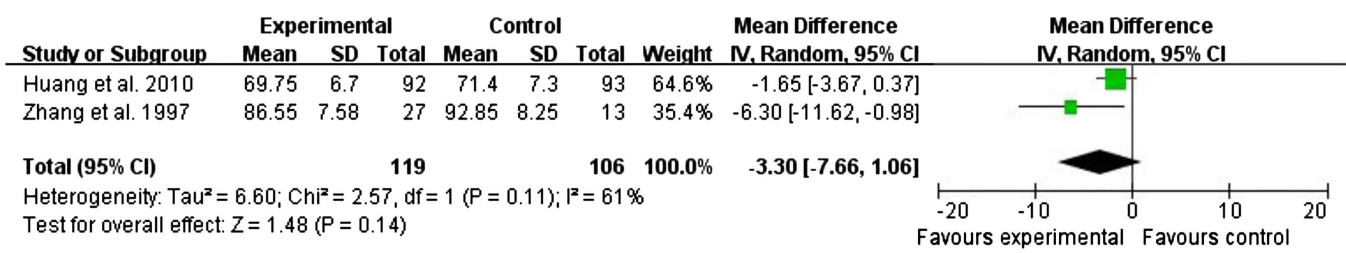

(b) DBP

\section{B Decoction}

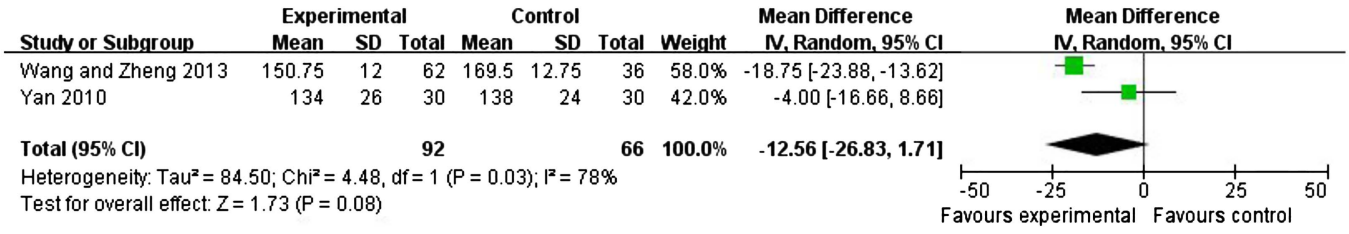

(a) SBP

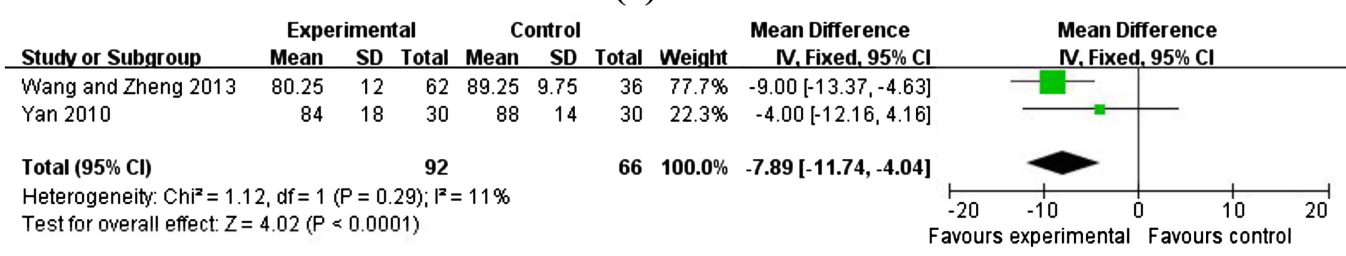

\section{(b) DBP}

\section{Injection}

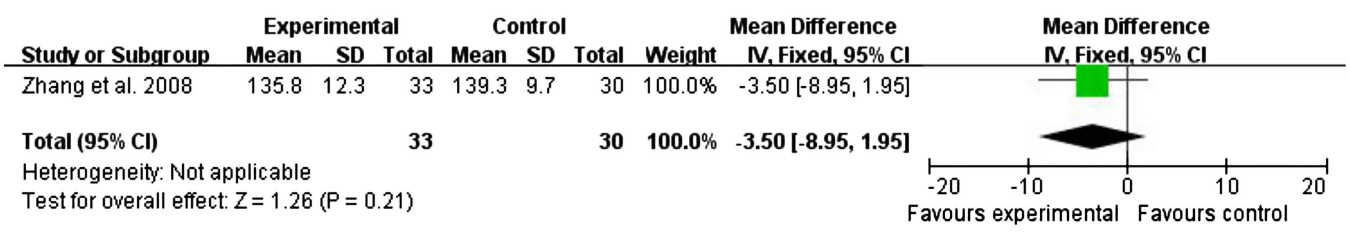

(a) SBP

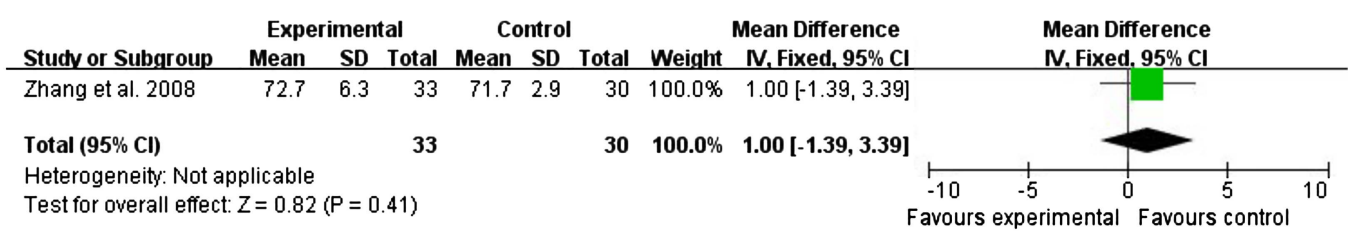

(b) DBP

Figure 3 Forest plot of the effect of Chinese herbal medicine on blood pressure.

group; they experienced nausea, vomiting and other gastrointestinal reactions $(p>0.05) .{ }^{30}$ No AEs were severe.

\section{Publication bias}

The number of included studies was too small (less than 10) to assess publication bias.

\section{DISCUSSION}

\section{Summary of evidence}

In Western medicine, control of persistently high BP is commonly accomplished by adding more/other types of antihypertensive drugs to the regimens of patients who are already receiving antihypertensive medications. However, in China, three-quarters of community health clinics 
provide both Western medicine and TCM treatments. ${ }^{38} 39$ Given a widespread perception in China that TCM is useful in human healthcare, it is not uncommon for TCM physicians to prescribe CHM as an adjunct to conventional Western medicine when managing hypertension. ${ }^{40} 41$ CHM is considered to have a positive add-on effect if the $\mathrm{BP}$ decreases to within the normal range, no matter how many or what types of antihypertensive drugs have already been used. ${ }^{42-44}$ Such an add-on design is currently a common practice and is widely employed in clinical studies of TCM for hypertension. ${ }^{45-47}$

This is the first reported attempt to assess the efficacy and safety of CHM for resistant hypertension by systematically reviewing reports published in English and Chinese. The overall results from the five included RCTs with 446 patients with resistant hypertension suggested that, compared with antihypertensive drugs alone, CHM (tablet) plus antihypertensive drugs clinically reduce SBP (decreased by $10.32 \mathrm{~mm} \mathrm{Hg}$ ) and DBP (decreased by $3.30 \mathrm{~mm} \mathrm{Hg}$ ); however, these reductions are not statistically significant. Moreover, CHM (decoction) plus antihypertensive drugs also produced a clinically meaningful reduction in SBP (decreased by $12.56 \mathrm{~mm} \mathrm{Hg}$ ); however, this change was also not statistically significant. CHM (decoction) plus antihypertensive drugs appear to be more effective in reducing DBP (decreased by $7.89 \mathrm{~mm} \mathrm{Hg}$ ). We found no significant difference between the effects of CHM (injection) plus antihypertensive drugs and antihypertensive drugs alone on SBP (decreased by $3.50 \mathrm{~mm} \mathrm{Hg}$ ) and DBP (increased by $1.00 \mathrm{~mm} \mathrm{Hg}$ ). Our review demonstrated that, when used as an adjunct to antihypertensive drugs, CHM may enhance their antihypertensive effect and be particularly beneficial for treating resistant hypertension.

\section{Limitations}

The generally poor quality and pronounced heterogeneity of the studies reviewed here should be taken into consideration. First, poor methodological design is one of the most common problems confronted by both complementary and alternative medicine. ${ }^{48-50}$ The primary studies had a number of methodological weaknesses. All five included trials declared randomisation; however, none detailed the methods of random sequence generation. Additionally, no study described allocation concealment. Therefore, the studies potentially had selection bias. A double-blind design is an important means of preventing outcomes from being influenced by either the placebo effect or observer bias. However, only one study has described the use of placebos and the blinding of participants and personnel. Blinding of outcome assessment was not reported by any trial. The lack of a placebo control was of critical concern for the included clinical trials and for TCM research as a whole. Some features associated with CHM may have restricted the use of placebos in these trials. For example, 'decoctions' were used in two trials. ${ }^{31} 34$ However, it is difficult to prepare a liquid (decoction) that has the same colour, taste and flavour as a placebo. ${ }^{51}$ One trial used an 'injection' and demonstrated positive results in terms of BP, blood rheology, fingernail microcirculation and blood sugar. ${ }^{33}$ However, the control group did not receive placebo injections; it is known that injections alone have a strong placebo effect. Therefore, we cannot rule out that the placebo effect was responsible for the overall effect of Chinese herbal injections. ${ }^{52}$ CHM was administered in 'tablet' form in two trials, ${ }^{30} 32$ one of which had a placebo control. Therefore, these findings should be interpreted conservatively. It is recommended that CHM be prepared in the form of a tablet, capsule, pill or injection in future trials. ${ }^{53}$ Information on dropout rates, withdrawals and intention-to-treat analysis was not provided, which might have led to attrition bias and other biases. Another important limitation of this systematic review was the inadequate reporting of mortality and progression to severe complications with long-term follow-up, which weakens the reliability and validity of recommendations. ${ }^{42}$ Moreover, significant clinical heterogeneity in the SBP and DBP was found. This heterogeneity may be strongly related to variations in methodological quality, participants, interventions and controls. Further, since only trials published in Chinese with 'positive results' regarding BP were included, potential publication bias cannot be completely ruled out. Additionally, since only one trial reported AEs, we had insufficient clinical data to draw definite conclusions concerning AEs. We therefore recommend that AEs of CHM be monitored rigorously and reported appropriately in future studies.

\section{CONCLUSIONS}

In summary, we can currently draw no firm conclusions about the effectiveness and safety of CHM for resistant hypertension. The methodological quality of the included trials was generally poor. Further rigorously designed clinical trials are warranted to more precisely ascertain the effectiveness and safety of CHM.

Additionally, future RCTs should avoid the limitations of the trials included in this systematic review by paying more attention to the following methodological issues: (1) adequate generation of allocation sequence and concealment of allocation; (2) appropriate methods of double blinding; (3) rational use of placebo controls; (4) strict reporting of dropouts and usage of intention-to-treat analysis; and (5) reporting of trials according to the recommendations of the CONSORT Statement. ${ }^{54}$

\section{Author affiliations}

${ }^{1}$ Department of Cardiology, Guang'anmen Hospital, China Academy of Chinese Medical Sciences, Beijing, China

${ }^{2}$ Bio-organic and Natural Products Laboratory, McLean Hospital, Harvard Medical School, Belmont, California, USA

${ }^{3}$ Department of Clinical Epidemiology and Biostatistics, McMaster University, Hamilton, Ontario, Canada

Acknowledgements The author would like to thank Trish Reynolds, a clinical specialist in medical oncology and psychotherapy from the Royal Australasian College of Physicians, in revising the English language of the manuscript. 
Contributors $\mathrm{XX}$ and $\mathrm{XL}$ designed the systematic review, performed data collection and extraction, contacted the original authors for missing or confusing information, carried out the statistical analysis and interpretation of the data, and wrote the first draft of the report. YZ and JW searched for articles, assessed their eligibility and performed a major revision of this report. When discrepancies occurred, they were resolved by discussion between $\mathrm{XX}, \mathrm{XL}, \mathrm{YZ}$ and JW. All authors approved the final version of the manuscript.

Funding $X X$ was supported by the National Natural Science Foundation Project of China (No. 81403375).

Competing interests None.

Provenance and peer review Not commissioned; externally peer reviewed.

Data sharing statement No additional data are available.

Open Access This is an Open Access article distributed in accordance with the Creative Commons Attribution Non Commercial (CC BY-NC 4.0) license, which permits others to distribute, remix, adapt, build upon this work noncommercially, and license their derivative works on different terms, provided the original work is properly cited and the use is non-commercial. See: http:// creativecommons.org/licenses/by-nc/4.0/

\section{REFERENCES}

1. Mancia G, Fagard R, Narkiewicz K, et al. 2013 ESH/ESC guidelines for the management of arterial hypertension: the task force for the management of arterial hypertension of the European Society of Hypertension (ESH) and of the European Society of Cardiology (ESC). Eur Heart J 2013;34:2159-219.

2. James PA, Oparil S, Carter BL, et al. 2014 Evidence-based guideline for the management of high blood pressure in adults report from the panel members appointed to the Eighth Joint National Committee (JNC 8). J Am Med Assoc 2014;311:507-20.

3. Ruilope LM. Current challenges in the clinical management of hypertension. Nat Rev Cardiol 2012;9:267-75.

4. Sarafidis PA, Georgianos P, Bakris GL. Resistant hypertension-its identification and epidemiology. Nat Rev Nephrol 2013:9:51-8.

5. Calhoun DA, Jones D, Textor S, et al. Resistant hypertension: diagnosis, evaluation, and treatment: a scientific statement from the American Heart Association Professional Education Committee of the Council for High Blood Pressure Research. Circulation 2008;117:510-26.

6. Daugherty SL, Powers JD, Magid DJ, et al. Incidence and prognosis of resistant hypertension in hypertensive patients. Circulation 2012;125:1635-42.

7. Solini A, Ruilope LM. How can resistant hypertension be identified and prevented? Nat Rev Cardiol 2013;10:293-6.

8. Hanselin MR, Saseen JJ, Allen RR, et al. Description of antihypertensive use in patients with resistant hypertension prescribed four or more agents. Hypertension 2011;58:1008-13.

9. Brook RD, Appel LJ, Rubenfire M, et al. Beyond medications and diet: alternative approaches to lowering blood pressure. Hypertension 2013;61:1360-83.

10. Dimeo F, Pagonas N, Seibert F, et al. Aerobic exercise reduces blood pressure in resistant hypertension. Hypertension 2012;60:653-8.

11. Wang J, Feng B, Yang XC, et al. Tai Chi for essential hypertension. Evid Based Complement Alternat Med 2013;2013:e215254, 1-10.

12. Lee MS, Pittler M, Guo RL, et al. Qigong for hypertension: a systematic review of randomized clinical trials. $J$ Hypertens 2007;25:1525-32.

13. Posadzki P, Cramer H, Kuzdzal A, et al. Yoga for hypertension: a systematic review of randomized clinical trials. Complement Ther Med 2014;22:511-22.

14. Flachskampf FA, Gallasch J, Gefeller O, et al. Randomized trial of acupuncture to lower blood pressure. Circulation 2007;115:3121-9.

15. Xiong XJ, Liu W, Yang XC, et al. Moxibustion for essential hypertension. Complement Ther Med 2014;22:187-95.

16. Lee MS, Choi TY, Shin BC, et al. Cupping for hypertension: a systematic review. Clin Exp Hypertens 2010;32:423-5.

17. Xiong XJ, Li SJ, Zhang YQ. Massage therapy for essential hypertension: a systematic review. J Hum Hypertens 2014. doi:10.1038/jhh.2014.52

18. Pimenta E, Gaddam KK, Oparil S, et al. Effects of dietary sodium reduction on blood pressure in subjects with resistant hypertension: results from a randomized trial. Hypertension 2009;54:475-81.
19. Xiong XJ, Yang XC, Liu YM, et al. Chinese herbal formulas for treating hypertension in traditional Chinese medicine: perspective of modern science. Hypertens Res 2013;36:570-9.

20. Mashour NH, Lin Gl, Frishman WH. Herbal medicine for the treatment of cardiovascular disease. Arch Intern Med 1998;158:2225-34.

21. Wang J, Xiong XJ. Current situation and perspectives of clinical study in integrative medicine in China. Evid Based Complement Alternat Med 2012;2012:e268542, 1-11.

22. Wang J, Wang $P Q$, Xiong XJ. Current situation and re-understanding of syndrome and formula syndrome in Chinese medicine. Internal Med 2012;2:e1000113, 1-5.

23. Mansoor GA. Herbs and alternative therapies in the hypertension clinic. Am J Hypertens 2001;14:971-5

24. Xiong XJ, Yang XC, Liu W, et al. Trends in the treatment of hypertension from the perspective of traditional Chinese medicine. Evid Based Complement Alternat Med 2013;2013:e275279, 1-13.

25. Vora CK, Mansoor GA. Herbs and alternative therapies: relevance to hypertension and cardiovascular diseases. Curr Hypertens Rep 2005;7:275-80.

26. Zhang GP, Jin HM, Long JJ, et al. Effect of ganoderma lucidum (ling zhi) combined with hypotensor on blood sugar, plasma NO, microcirculation and hemorrheology in treatment of refractory hypertension. J Chin Micro 1999;3:75-8.

27. Liu SC, Wang HX, Hou XM, et al. Clinical research of modified qi ju dihuang decoction on resistant hypertension in elderly. J Emerg Tradit Chin Med 2011;20:1729-30.

28. Zhu ZP, Peng C. Effect of warming kidney yang therapy combined with western medicine on 23 cases of resistant hypertension. $J$ Sichuan Tradit Chin Med 2012;30:83-4.

29. Higgins JPT, Green S. Cochrane handbook for systematic reviews of interventions, Version 5.1.0. The Cochrane Collaboration. 2011. http://handbook.cochrane.org/

30. Huang SX, Liu YL, Huang J, et al. Long-term efficacy of salvia on patients with resistant hypertension complicated with hyperlipidemia. J Guangmin Tradit Chin Med 2010;25:1415-16.

31. Wang JY, Zheng X. Clinical observation of drinking for angelica and astragalus on refractory hypertension. $J$ Hebei Tradit Chin Med 2013;35:817-19.

32. Zhang GP, Long JJ, Qian RZ, et al. Significance and changes of blood sugar, blood lipid, microcirculation and hemorheology during treatment of hypertension by linzhi combined with hypotensor. Chin J Micro 1997;7:34-6.

33. Zhang Q, Yang YM, Yu GY. Effects of gastrodin injection on blood pressure and vasoactive substances in treatment of old patients with refractory hypertension: a randomized controlled trial. J Chin Integr Med 2008;6:695-9.

34. Yan BY. Clinical observation of integrative medicine for refractory hypertension. J Guangmin Tradit Chin Med 2010;25:1263-4.

35. Tachjian A, Maria V, Jahangir A. Use of herbal products and potential interactions in patients with cardiovascular diseases. J Am Coll Cardiol 2010;55:515-25.

36. Ernst E. 'First, do not harm' with complementary and alternative medicine. Trends Pharmacol Sci 2007;28:48-50.

37. Valli G, Giardina EG. Benefits, adverse effects and drug interactions of herbal therapies with cardiovascular effects. J Am Coll Cardiol 2002;39:1083-95.

38. Tang JL, Liu BY, Ma KW. Traditional Chinese medicine. Lancet 2008;372:1938-40.

39. $\mathrm{Xu} \mathrm{H}$, Chen $\mathrm{KJ}$. Integrative medicine: the experience from China $J$ Altern Complement Med 2008;14:3-7.

40. Wang J, Xiong XJ. Control strategy on hypertension in Chinese medicine. Evid Based Complement Alternat Med 2012;2012: e284847, 1-6.

41. Wang J, Xiong XJ. Evidence-based Chinese medicine for hypertension. Evid Based Complement Alternat Med 2013;2013: e978398, 1-12.

42. Wang J, Xiong XJ. Outcome measures of Chinese herbal medicine for hypertension: an overview of systematic reviews. Evid Based Complement Alternat Med 2012;2012:e697237, 1-10.

43. Xiong XJ, Liu W, Yang XC, et al. Ginkgo biloba extract for essential hypertension: a systemic review. Phytomedicine 2014;21:1131-6.

44. Xiong XJ, Yang XC, Feng B, et al. Zhen gan xi feng decoction, a traditional Chinese herbal formula, for the treatment of essential hypertension: a systematic review of randomized controlled trials. Evid Based Complement Alternat Med 2013;2013:e982380, 1-9.

45. Wang J, Yao KW, Yang XC, et al. Chinese patent medicine liu wei di huang wan combined with antihypertensive drugs, a new integrative medicine therapy, for the treatment of essential hypertension: a systematic review of randomized controlled trials. Evid Based Complement Alternat Med 2012;2012:e714805, 1-7. 
46. Wang J, Feng B, Yang XC, et al. Tianma gouteng yin as adjunctive treatment for essential hypertension: a systematic review of randomized controlled trials. Evid Based Complement Alternat Med 2013;2013:e706125, 1-18.

47. Wang J, Yang XC, Feng B, et al. Is Yangxue Qingnao granule combined with antihypertensive drugs, a new integrative medicine therapy, more effective than antihypertensive therapy alone in treating essential hypertension? Evid Based Complement Alternat Med 2013;2013:e540613, 1-8.

48. Kinsel JF, Straus SE. Complementary and alternative therapeutics: rigorous research is needed to support claims. Annu Rev Pharmacol Toxicol 2003;43:463-84

49. Tang JL, Zhan SY, Ernst E. Review of randomised controlled trials of traditional Chinese medicine. BMJ 1999;319:160-1.
50. Hawkes D, Benhamu J. Pharmacological examination of TCM should be evidence based. Trends Pharmacol Sci 2014;35:111-12.

51. Sarris J. Chinese herbal medicine for sleep disorders: poor methodology restricts any clear conclusion. Sleep Med Rev 2012;16:493-5

52. Chen W, Lin CD, Kang HJ, et al. Chinese herbal medicines for the treatment of Type A H1N1 Influenza: a systematic review of randomized controlled trials. PLoS One 2011;6:e28093, 1-7.

53. Rathbone J, Zhang L, Zhang M, et al. Chinese herbal medicine for schizophrenia. Cochrane Database Syst Rev 2005;11;(4): CD003444.

54. Moher D, Hopewell S, Schulz KF, et al. CONSORT 2010 Explanation and Elaboration: updated guidelines for reporting parallel group randomised trial. J Clin Epidemiol 2010;63:1-37. 